\title{
WILDFIRE SMOKE TRANSPORT AND IMPACT ON AIR QUALITY OBSERVED BY A MULLTI-WAVELENGTH ELASTIC-RAMAN LIDAR AND CEILOMETER IN NEW YORK CITY Yonghua Wu, Wilson Peña, Barry. Gross, Fred Moshary*
}

NOAA-CREST and the City College of New York, NY, NY 10031, USA. *moshary@ccny.cuny.edu

\begin{abstract}
The intense wildfires from the western Canada in May 2016 injected large amount of smoke into the atmosphere. This paper presents integrated observation of the event by a lidar, ceilometer, and satellite together with models and an assessment of smoke plume impacts on local air quality in New York City (NYC) area. A dense aloft plume on May 20 and a boundary layer plume on May 25 are analyzed. The smoke mixing into planetaryboundary-layer (PBL) and strong diurnal variation of PBL-top are shown. For the $2^{\text {nd }}$ case, the ground $\mathrm{PM}_{2.5}$ measurements show a significant increase in both the urban and upwind non-urban areas of NYC. The smoke sources and transport paths are further verified by the satellite observations and HYSPLIT model data.
\end{abstract}

\section{INTRODUCTION}

An intense wildfire began on May 1, 2016, roared into Fort McMurray, Alberta, Canada, forcing the largest wildfire evacuation in the province's history https://en.wikipedia.org/wiki/Fort_McMurray).

The wildfire spread across approximately $1,500,000$ acres across northern Alberta and into Saskatchewan before it was declared to be under control on July 5, 2016. The smoke from the wild fires travelled across the US to the Gulf coast, even to Europe according to the satellite imageries (https://weather.com/science/environment/news/fo rt-momurray-wildfire-smoke-travels-europe). The emissions from the wild fires include aerosols and gaseous compounds such as carbon monoxide $(\mathrm{CO})$, carbon dioxide $\left(\mathrm{CO}_{2}\right)$, nitrogen oxide (NOx), etc., and can adversely affect the downwind air quality and climate radiation in the regionalcontinental scale through long-range transport [1].

In addition, the wildfire emissions have acute or long-term health implications on the exposed populations, according to the various health agencies. Among the major components of wildfire smoke, fine particles $\left(\mathrm{PM}_{2.5}\right)$ affect ambient air quality and have various effects on human health [2]. The study by Le et al. [3] suggests that rapid increases in $\mathrm{PM}_{2.5}$ concentrations resulting from wildfire smoke can affect the health of elderly populations with increased rate of hospitalization for respiratory and cardiovascular diagnoses in the downwind area thousands of kilometers away from the fires. Weber et al. [4] show that high $\mathrm{PM}_{2.5}$ exposures is associated with increased risk of asthma, myocardial infarction and heart failure in NYC metropolitan and surrounding areas.

In this study, the observations of Canadian smoke plume transport to NYC are analyzed with a multi-wavelength Elastic-Raman lidar, a ceilometer (Vaisala CL-51), an AERONET sun/sky radiometer, satellite observations and the model output products on May 20 and 25, 2016. Ground $\mathrm{PM}_{2.5}$ in the urban and upwind non-urban area of NYC are also investigated to assess the smoke influences on the local air quality, as well as its speciation such as organic carbon (OC), elemental carbon (EC) and sulfate. Transport paths and origins of smoke plumes are investigated by the NOAA-HMS (Hazard Mapping System) fire and smoke product and HYSPLIT backward trajectory analysis.

\section{METHODOLOGY}

At CCNY, a suite of ground-based remote sensing instruments are deployed on a building roof, near a standard surface air quality monitoring station by the New York State Department of Environment Conservation. The instruments include a 3wavelength Elastic-Raman lidar, a ceilometer, and an AERONET Cimel sun/sky radiometer. The lidar transmits three wavelengths (1064-, 532- and 355$\mathrm{nm})$ with a flash lamp-pumped Nd: YAG laser at a repetition rate of $30 \mathrm{~Hz}$ (Spectra-physics QuantaRay PRO-320) [5]. Three elastic-scattering and two Raman-scattering returns by nitrogen and water vapor molecules excited by $355-\mathrm{nm}$ laser output are collected by a receiver telescope (Ø50- 
$\mathrm{cm})$. The signals are acquired by LICEL transient recorders (TR40-160) and recorded with 1-min average, and full return signals are detected with the starting altitude $0.5 \mathrm{~km}$. The ceilometer measures laser backscatter at a wavelength of 910 $\mathrm{nm}$ with a range resolution of $10 \mathrm{~m}$ [6]. It makes fully automatic 24-hr/7-day observations in allweather condition. It provides attenuated backscatter and calibrated range-corrected backscatter coefficient products, which allows monitoring of the PBL process and evolution for air pollution studies. The aerosol contribution in the lidar overlap region $(<0.5-\mathrm{km})$ can be corrected by using the ceilometer-measured backscatter profile near the surface or by extending a constant of aerosol extinction at $0.5 \mathrm{~km}$ to the surface. In addition, AERONET products from a Cimel sun/sky radiometer provide column aerosol optical depth (AOD), Angstrom exponent (AE), microphysical parameters (volume size distribution and refractive index and singlescattering albedo [7]. The AOD can be used to constrain the lidar-ratio in the lidar retrieval of aerosol extinction profile under clear sky.

\section{RESULTS and DISCUSSION}

\subsection{Case-1: Aloft plumes on May 20, 2016}

Figure 1(a) shows the aloft plumes at $5 \sim 7 \mathrm{~km}$ altitude observed by the lidar on May 20,2016. The aerosol extinction coefficients in the aloft layer are much larger than the ones in the PBL, and some thin layers are seen below 5-km. The Angstrom exponents in Fig.1(b) are around 1.8 in the aloft layer, which indicate a fine-mode dominant particle size distribution. They are likely associated with the smoke. The total AOD attains 0.4 at 532$\mathrm{nm}$ and are mostly contributed from the aloft plume as shown in Fig.1(c). Meanwhile, the satellite NOAA-GASP (GOES Aerosol/Smoke Product) AOD map clearly shows a high-AOD belt (red color in Fig.1d) from Canada to NYC area, which indicates the smoke transport path. Furthermore, Fig.1(e) shows the wildfire point sources (red +) and smoke area (yellow) from the NOAA-HMS product, and the air backward trajectories with the end point at $\mathrm{CCNY}$ at 5- and 7-km altitude, 60-hour duration from the NOAA-HYSPLIT model. The results indicate that the main wildfire points were located in the west Canada and the border of USCanada, and an area of light to moderately dense residual smoke was moving east across a large
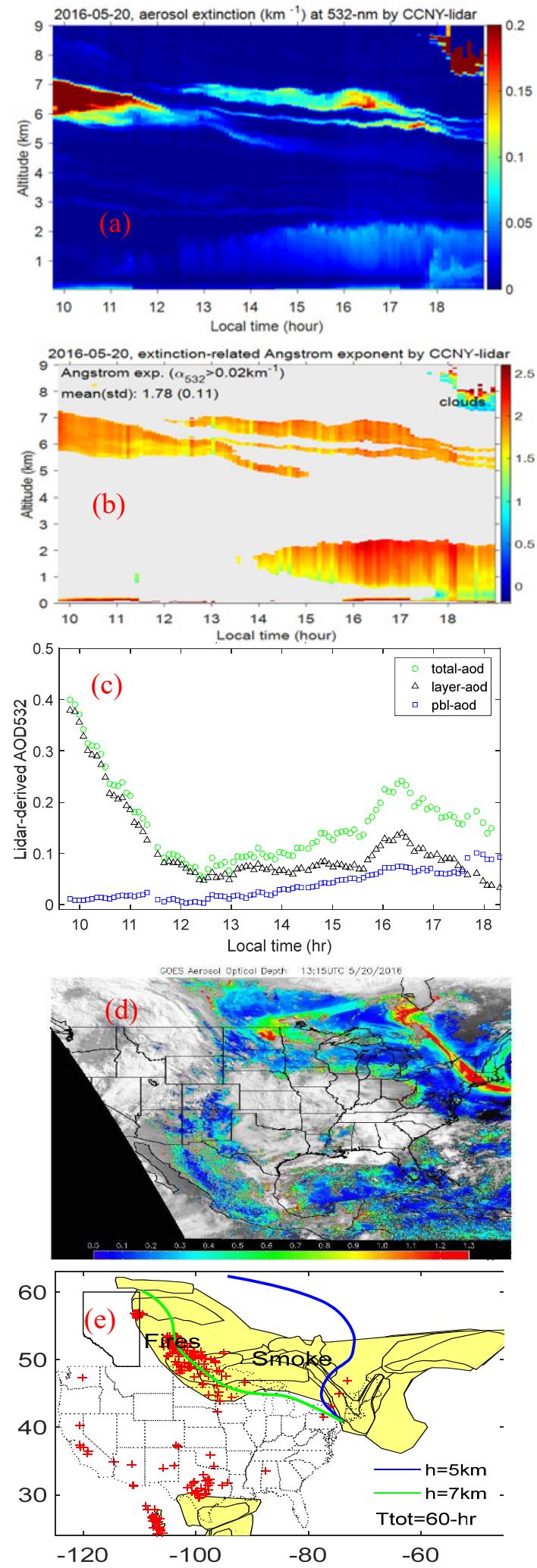

Fig.1 (a)-(c) Aerosol extinction, Angstrom exponent and AOD from the CCNY-lidar, (d) AOD spatial distribution from NOAA-GASP, (e) Fire points (red+) and smoke (yellow) and trajectories on May 20, 2016. 
Section of the northern US/southern/eastern Canada.

\subsection{Case-2: PBL-plumes on May 25, 2016}

Figure 2 shows the time-height distributions of aerosols measured by the ceilometer and lidar on May 25, 2016. Fig.2(a) indicates two aerosol layers in the PBL: one below 1-km starting from 6:00 am and other one at $\sim 3 \mathrm{~km}$ at noon. In particular, the PBL-tops showed a dramatic increase that reached up to $3 \mathrm{~km}$ in the afternoon, which indicate strong convective or turbulent process that resulted in plumes mixing well within the PBL. In Fig.2(b) from the lidar daytime measurements, the high PBL-tops over the convective daytime period are consistent with the ceilometer data while there are some aloft aerosols observed above the PBL. The aerosol extinction coefficients are derived from the CCNY-lidar and are shown in Fig. 2c. On May 25, the extinction of aerosols was as high as $0.2 \mathrm{~km}^{-1}$ at 532-nm with the Angstrom exponents of 1.5 1.7. Meanwhile, the consistent aerosol extinctions at $355-\mathrm{nm}$ between the two independent retrievals from the Raman- and Mie-scattering signals, indicate the reliability of retrievals. In addition, the lidar-derived aerosol optical depths vary from 0.2 to 0.4 at $532-\mathrm{nm}$. The mean of Raman-lidar derived lidar ratio in the PBL is $62.7+/-11 \mathrm{sr}$ at $355-\mathrm{nm}$.

Figure 3 shows the fires sources (red + ), smoke areas (yellow) and air back-trajectories with the ending point at CCNY (urban), Queens College(urban) and Newburgh (non-urban) sites (12:00 UTC, 72-hr long, at the altitudes of $0.5-\mathrm{km}$, $1-\mathrm{km}$ and $2-\mathrm{km})$. Interestingly, the similar trajectories of transport are indicated among the three sites and at the different altitudes. There were numerous wildfires at Fort McMurray in Alberta, Canada and some wildfires in the southwest US. The trajectories indicate that the aloft smokes over NYC was transported from Canada.

Figure 4 gives the temporal variation of ground $\mathrm{PM}_{2.5}$ in the urban (CCNY) and nonurban (Newburgh) or upwind areas of NYC on May 2429, 2016. A significant increase can be seen starting on May 25; and the $\mathrm{PM}_{2.5}$ concentrations show consistent temporal variation at these sites. The $\mathrm{PM}_{2.5}$ concentrations at $\mathrm{CCNY}$ and Newburgh were well correlated $(\mathrm{R}=0.84)$. Such good correlation probably indicates that the $\mathrm{PM}_{2.5}$ at the urban and upwind non-urban sites were from the similar sources, which is consistent
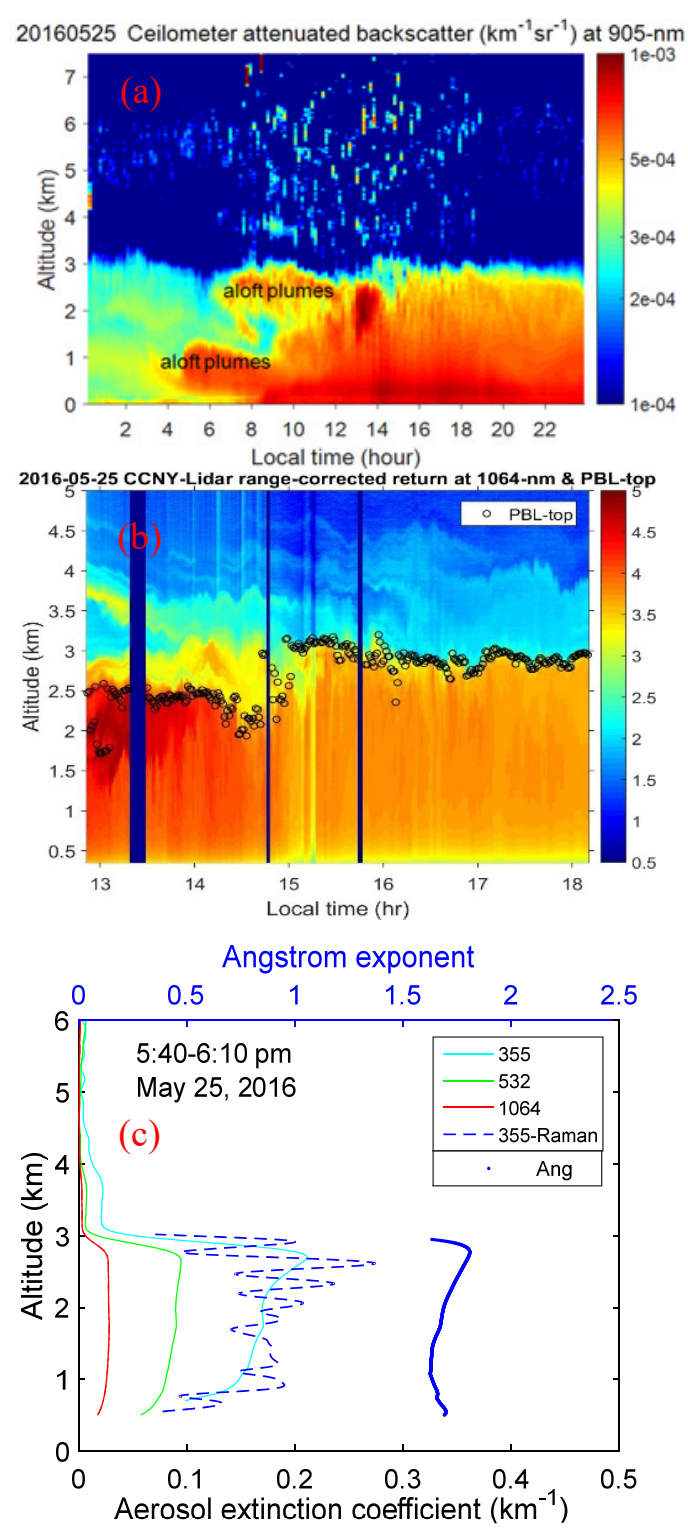

Fig.2 Attenuated backscatter, extinction and Angstrom exponent from ceilometer and lidar on May 25, 2016

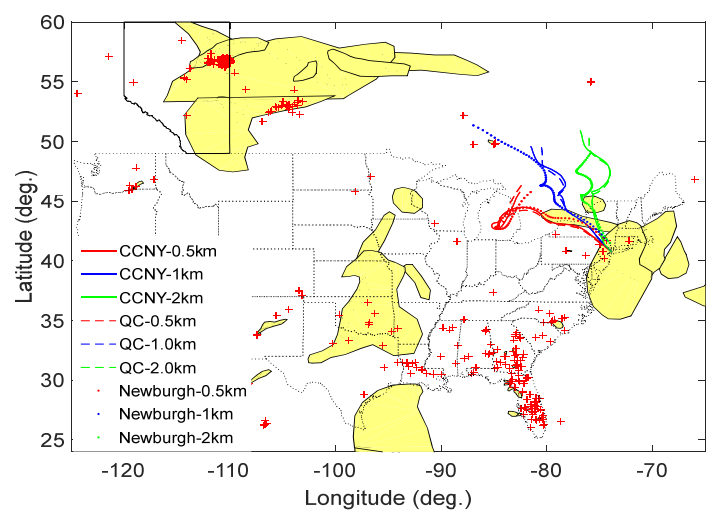

Fig.3 Fire sources (red+), smoke (yellow), backward trajectories (green-black lines) by NOAA-HMS and HYSPLIT model on May 25 
with the long-range transport of aerosols.

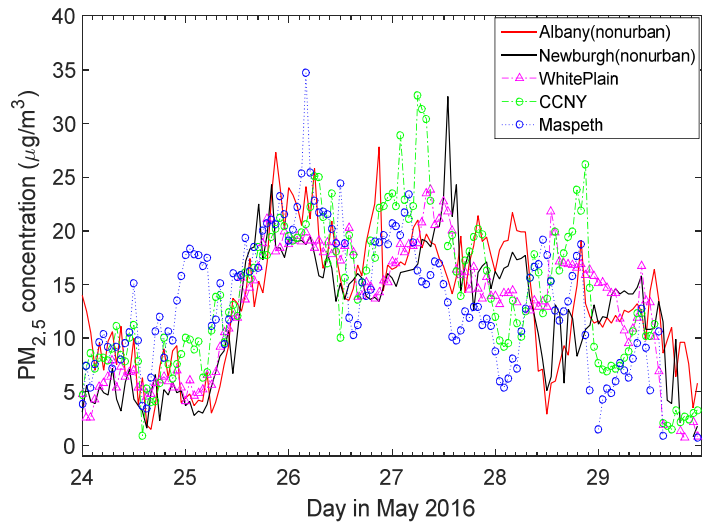

Fig.4 Ground $\mathrm{PM}_{2.5}$ concentrations in the urban and upwind non-urban area of NYC.

We analyzed the temporal variation of the $\mathrm{OC}$, $\mathrm{EC}$, sulfate of $\mathrm{PM}_{2.5}$ and trace gases $\left(\mathrm{CO}\right.$ and $\left.\mathrm{O}_{3}\right)$ at Queen College site in NYC. Both the OC and EC showed consistent increase for this event. For instance, the OC increased from $2 \mu \mathrm{g} / \mathrm{m}^{3}$ to $8 \mu \mathrm{g} / \mathrm{m}^{3}$ while the EC increased up to $4 \mu \mathrm{g} / \mathrm{m}^{3}$. Meanwhile, the sulfate also indicated an increase trend. These values are much larger than the monthly average of OC $\left(1.0 \sim 4 \mu \mathrm{g} / \mathrm{m}^{3}\right)$, EC $\left(0.5 \sim 1.4 \mu \mathrm{g} / \mathrm{m}^{3}\right)$ and sulfate $\left(1 \sim 3 \mu \mathrm{g} / \mathrm{m}^{3}\right)$ in NYC $[8,9]$. Thus, the results indicate the smoke-like plume transport and mixture with the industrial aerosols (sulfate) in the upwind region along the transport paths. Furthermore, the peak values of hourly ozone concentrations on May 25-26 were greater than the NAAQS value of $70 \mathrm{ppb}$.

\section{CONCLUSIONS}

This paper analyzes two episodes of the wildfire smoke transport from Canada to NYC on May 20 and 25, 2016. The optical properties of aerosols and their influences on the local air quality are assessed. Aloft plumes at $6 \sim 7 \mathrm{~km}$ on May 20, contributed to the total AOD. The PBL-plumes below $3-\mathrm{km}$ on May 25 are well mixed and the strong diurnal variation of PBL-top are demonstrated from the profiling observations of ceilometer and lidar, along with and strong convection process and high PBL-top at $\sim 3 \mathrm{~km}$ in the daytime. Importantly, the ground $\mathrm{PM}_{2.5}$ concentrations show consistent increase from 5 to $30 \mu \mathrm{g} / \mathrm{m}^{3}$ in the urban and upwind non-urban area of NYC, and a good correlation $(\mathrm{R}=0.8)$ indicates similar sources that for the regional transport event.
The increases of OC, EC and sulfate indicate the smoke plumes transport and mixture with the industrial emissions in the upwind area of the region studies. The sources and transport paths from the western Canada to the site are clearly demonstrated by the NOAA-HMS and HYSPLIT model.

ACKNOWLEDGEMENTS. This study was supported by National Oceanic and Atmospheric Administration (NOAA) under the CREST Grant \# NA11SEC4810004.

\section{References}

[1] Liu, Y., and et al., 2014: Wildland fire emissions, carbon, and climate: Wildfireclimate interactions. Forest Ecol. Manage., 317, 80-96.

[2] Fann, N., et al., 2016: Ch.3: Air Quality Impacts. The Impacts of Climate Change on Human Health in the United States: A Scientific Assessment. U.S. Global Change Research Program, Washington, DC, 69-98.

[3] Le, G. E., et al., 2014: Canadian Forest Fires and the Effects of Long-Range Transboundary Air Pollution on Hospitalizations among the Elderly, ISPRS Int. J. Geo-Inf., 3, 713-731.

[4] Weber, S. A., et al., 2016: Assessing the impact of fine particulate matter (PM2.5) on respiratory-cardiovascular chronic diseases in the New York City Metropolitan area using Hierarchical Bayesian Model estimates, Environ. Res., 151, 399-409.

[5] Wu, Y., S. Chaw, B. Gross, et al., 2009: Low and optically thin cloud measurements using a Raman-Mie lidar, Appl. Opt., 48, 1218-1227.

[6] Münkel, C., et al., 2004: New optical concept for commercial lidar ceilometers scanning the boundary layer. Proc. SPIE, 5571, 364-374.

[7] Holben, B.N., and et al., 1998: AERONET A federated instrument network and data archive for aerosol characterization, Rem. Sens. Environ., 66, 1-16.

[8] Rattigan, O. V., et al., 2010: Multi-year hourly PM2.5 carbon measurements in New York: Diurnal, day of week and seasonal patterns, Atmos. Environ., 44 (16), 2043-2053.

[9] Rattigan, O. V., et al., 2016: Long Term Trends in New York: $\mathrm{PM}_{2.5}$ Mass and Particle Components, Aerosol and Air Quality Research, 16(5), 1191-1205. 